\title{
MARCUS GUNN PHENOMENON ASSOCIATED WITH SYNKINETIC OCULO-PALPEBRAL MOVEMENTS*
}

\author{
BY
}

\author{
R. S. GARKAL \\ Department of Ophthalmology, Irwin Hospital, New Delhi, India
}

THE Marcus Gunn phenomenon is a well-known clinical entity wherein abnormal palpebral movements are associated with movements of the jaw.

No record has been found in the literature of a case in which an associated concomitant convergent strabismus corrected itself automatically with the elevation of the ipsilateral ptotic lid when the jaw was opened or when ptosis was passively or surgically corrected.

A case showing this congenital anomaly is described below.

\section{Case Report}

A female aged 16 years had a partial congenital ptosis of the left upper lid with concomitant convergent strabismus of about $15^{\circ}$ on the same side (Fig. 1). Movements of both the eyes were normal. On opening the jaw or twisting the mouth to the right (i.e. to the opposite side), the ptosis and the squint corrected themselves (Figs 2 and 3 ).

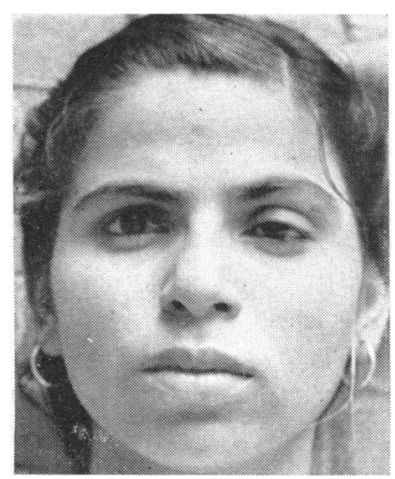

FIG. 1.-Pre-operative left ptosis and convergent strabismus.

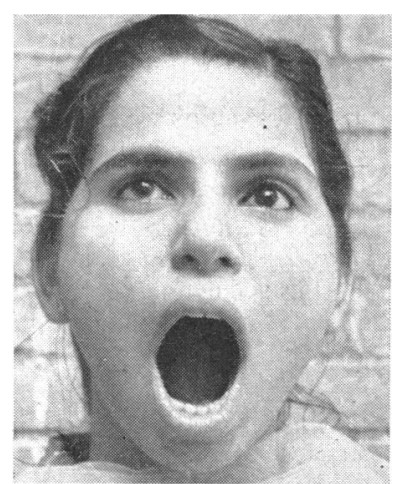

FIG. 2.-Marcus Gunn phenomenon.

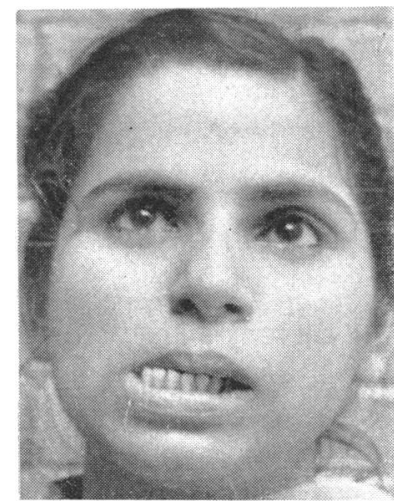

FIG. 3.-On twisting the mouth to the opposite side, the ptosis and convergence of left eye are corrected.

* Received for publication November 24, 1960. 566 
On twisting the mouth to the left (i.e. to the same side), the ptosis and the squint remained unaffected (Fig. 4).

When the left upper lid was lifted passively, the squint also disappeared (Fig. 5).

After a Blaskovicz operation to the left upper lid, the ptosis as well as the squint was corrected (Fig. 6).

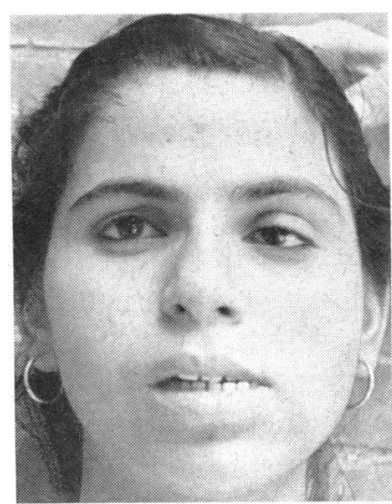

Fig. 4.-On twisting the mouth to the same side, the ptosis and convergence are unaffected.

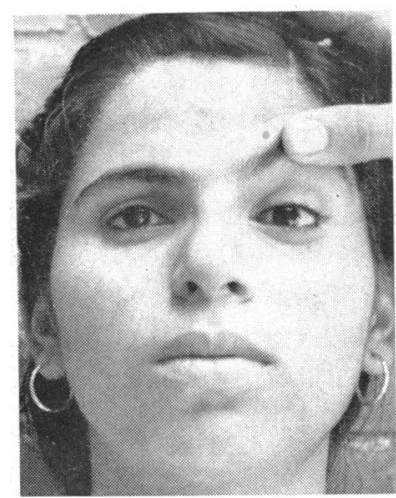

FIG. 5.-On passively lifting the ptotic lid the convergence is corrected.

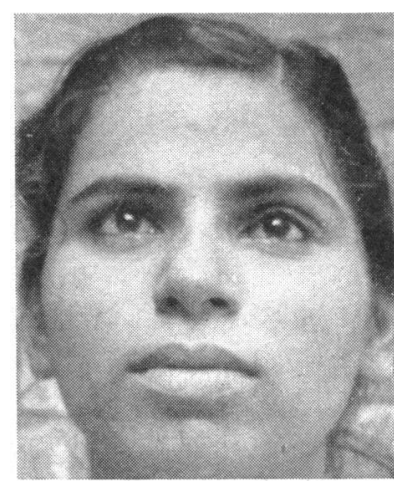

Fig. 6.-After surgical correction of the left ptotic lid, the convergence was automatically corrected.

\section{Summary}

A case is reported with unilateral congenital ptosis of the Marcus Gunn type with the unusual accompaniment of convergent strabismus in the same eye.

Elevation of the ptotic lid was followed by the automatic correction of the convergent strabismus.

I am grateful to Dr. N. S. Jain, Head of the Department of Ophthalmology, Irwin Hospital, for his help in the preparation of this paper. 